\title{
Verificação da prevalência de queixas osteomusculares em funcionários de uma farmácia em Pato Branco-PR
}

\author{
Sandra Mara de F.C. Martins \\ Veruska Halana Seider da Silva \\ Willian Felipe Carra \\ Claudio Oliveira Santos \\ Hellen Lunardi \\ Evandro Antônio Maciel \\ Luciana Cardoso da Silveira \\ Alexandra Karini de Moraes da Silva \\ Guilherme Augusto Moreira
}

CADERNO DE RESUMOS

Fisisenectus. Unochapecó

Ano 1 - Edição especial - 2013

p. 131

Guilherme Augusto Moreira, acadêmico do curso de Fisioterapia (FADEP-Pato Branco), guilhermeamoreira@hotmail.com

\begin{abstract}
Resumo
Introdução: Os funcionários que trabalham em farmácias e drogarias desempenham, entre outras, a função de balconistas e/ou atendentes. Como outros trabalhadores, podem apresentar patologias ocupacionais decorrentes de fatores originados no ambiente físico ou acarretados pela sobrecarga postural em consequência de um grande período em posição ortostática e do trabalho repetitivo, porém pesquisas realizadas para o entendimento quanto à saúde do trabalhador são escassas em relação a esse profissional. Objetivos: Identificar a prevalência de queixas osteomusculares decorrentes do trabalho em uma farmácia e verificar o risco de ocorrência do evento para futura estruturação de um modelo de atendimento fisioterápico e de prevenção dos sintomas. Metodologia: A pesquisa foi desenvolvida nos meses de maio e junho de 2013, em um estudo transversal de caráter investigativo, em uma farmácia com 16 funcionários, média de idade de $33 \pm 4$ anos, para a averiguação de queixas que possam caracterizar o diagnóstico de LER/DORT. O recurso metodológico utilizado foi o Questionário Nórdico para Análise de Sintomas de Comprometimento Osteomuscular proposto por Kuorinka et al., validado no Brasil por Pinheiro. Resultados: A taxa de prevalência foi de $81,25 \%$. A pesquisa realizada com os funcionários averiguou que do total de 16 funcionários, $\mathrm{N}=13$, referiram algum incômodo osteomuscular, e $\mathrm{N}=3(9,25 \%)$ não relataram queixa. A região de maior queixa foi a lombar e a da perna com $\mathrm{N}=4$ queixas $(30,76 \%)$, seguidas das regiões do pescoço, punho e joelhos; com o incômodo apresentando há mais de três anos indicando cronificação destes e com reincidência de uma a duas vezes ao ano, com intensidade referida como moderada. A região que suscitou maior procura por atendimento médico foi a do pescoço, ombros e coluna, sendo que essas regiões evidenciam a sobrecarga postural. Quanto à adoção de medidas para alívio dos sintomas, os entrevistados referem uso de medicamentos ou outras medidas não informadas, salienta-se aqui que a Fisioterapia foi procurada somente por um dos entrevistados. Considerações finais: A prevalência de queixas osteomusculares é significativa entre os funcionários que trabalham na farmácia. As queixas podem ser conclusivas de acometimento por LER, dada a frequência, distribuição anatômica e periodicidade que acontecem. Recomendam-se o prosseguimento da pesquisa para que inclua a compreensão do ambiente de trabalho. Entende-se que é necessário estender a estes funcionários a atenção de um programa de prevenção e de atendimento fisioterápico.
\end{abstract}

\section{Palavras-chave}

Saúde coletiva. DORT. Trabalhadores 